\title{
SNS CRYOGENIC SYSTEMS COMMISSIONING
}

\author{
D. Hatfield ${ }^{1}$, F. Casagrande ${ }^{1}$, I. Campisi ${ }^{1}$, P. Gurd ${ }^{1}$, M. Howell ${ }^{1}$,

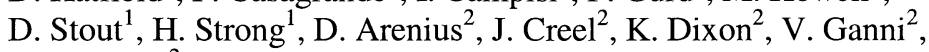 \\ P. Knudsen ${ }^{2}$ \\ ${ }^{1}$ SNS Project, Oak Ridge National Laboratory, Tennessee, 37831, USA \\ ${ }^{2}$ Thomas Jefferson National Accelerator Facility (TJNAF) \\ Newport News, Virginia, 23606, USA
}

\begin{abstract}
The Spallation Neutron Source (SNS) is under construction at Oak Ridge National Laboratory. The cold section of the Linac consists of 81 superconducting radio frequency cavities cooled to $2.1 \mathrm{~K}$ by a 2400 watt cryogenic refrigeration system. The major cryogenic system components include warm helium compressors with associated oil removal and gas management, $4.5 \mathrm{~K}$ cold box, $7000 \mathrm{~L}$ liquid helium dewar, $2.1 \mathrm{~K}$ cold box (consisting of 4 stages of cold compressors), gaseous helium storage, helium purification and gas impurity monitoring system, liquid nitrogen storage and the cryogenic distribution transfer line system. The overall system commissioning and future plans will be presented.
\end{abstract}

KEYWORDS: Accelerator Technology, 2.1K Cryogenic Systems

PACS: 07.20.Mc, 29.25.Dz, 29.17.+w

\section{INTRODUCTION}

The SNS cryogenic system follows the TJNAF design with some modifications and with about sixty percent of the refrigeration capacity. FIGURE 1 is a block diagram of the cryogenic system. TABLE 1 lists major cryogenic system load parameters. For a detailed description of the system design and loads see Ref. [1-3, 4].

The control system is an important and integral part of the SNS cryogenic system. It uses EPICS (Experimental Physics and Industrial Control System) to perform operator interface and high level control functions. The EPICS monitoring and control software runs in VME (VERSAmodule Eurocard) based IOCs (Input/Output Controllers) and in "soft IOCs" in a Linux box. The IOCs perform all automatic control sequences and almost all Proportional Integral Differential (PID) control loops execution which includes 
temperature, pressure, flow, heater, cold compressor speed and valve position control. Operator interface workstations use the Linux operating system on standard personal computers. FIGURE 2 shows a typical operator workstation control screen. AllenBradley PLCs (Programmable Logic Controllers) are used to provide low level controls and also for equipment protection interlocks.

In addition, the $4.5 \mathrm{~K}$ cold box PLC contains all the software for protecting and optimizing the performance of the turbines. Most of the sensors and actuators are connected to the PLCs. The system includes $16 \mathrm{PLCs}, 11 \mathrm{IOCs}$, and 5 operator workstations. The design, programming, installation, checkout, and commissioning of the control system was performed by SNS personnel.

\section{COMMISSIONING}

The major subsystems were designed to be tested independently starting with the warm helium compressors, followed by the $4.5 \mathrm{~K}$ cold box (without the $2.1 \mathrm{~K}$ cold box) with a $20 \mathrm{~kW}$ primary and $10 \mathrm{~kW}$ shield load heaters, and finally the $2.1 \mathrm{~K}$ cold box. FIGURE 3 shows the System Test Configuration.

Commissioning of the warm compressors began in December 2003. The three first stage $400 \mathrm{~kW}$ and three second stage $1864 \mathrm{~kW}$ oil flooded Howden 321 screw compressors underwent the 160 hours acceptance test. The nominal operating system pressures are $0.1 \mathrm{MPa}$ for the first stage compressor suction, $0.4 \mathrm{MPa}$ for the inter stage header, and $1.68 \mathrm{MPa}$ for the second stage discharge pressure with a cold box supply flow of $1149 \mathrm{~g} / \mathrm{s}$. Only two compressors in each stage are required to provide full plant capacity. A number of initial problems were discovered, including reversed oil heat exchanger seals, oil relief valves and oil circuit bypass valves. The vendor quickly addressed these problems and corrected the deficiencies.

In May 2004 all the cold compressors' instrumentation electrical connectors (4 per compressor) were confirmed to be leaking. An analysis by the cold compressor manufacturer with the connector sub-supplier indicated the sub-supplier had lost the technology to produce connectors which could withstand cryogenic conditions. This cryogenic connector model had previously been used very successfully. After many months of iteration with the manufacturer to recapture the technology, we decided to move ahead with a feed-through design developed at SNS. The replacements from the cold compressor manufacturer have now been received and are in the process of being cold tested for acceptance.

In July 2004, the $4.5 \mathrm{~K}$ Cold Box liquefaction and refrigeration modes at nominal design ("T-S") conditions were tested. The plant met the $4 \mathrm{~K}$ liquefaction capacity requirement of $80 \mathrm{~g} / \mathrm{s}$. However, to achieve the $4.5 \mathrm{~K}$ refrigeration capacity it was necessary to reduce the intended 4 atm inter-stage system operating pressure to $2.8 \mathrm{~atm}$. For all tests the $\mathrm{LN}_{2}$ consumption was higher than the intended design, approximately $20 \%$ for the liquefaction mode and $50 \%$ for the refrigeration mode. From preliminary analysis it appears that the top heat exchanger is not performing to specification. We are working with the cold box manufacturer to evaluate the measures necessary to correct the current operating parameters and nitrogen consumption to the intended design goals.

In August 2004, the Cryogenic Distribution System [5] was successfully commissioned with one Medium Beta Cryomodule and only required simple cryogenic line connection from the supply branch to the return branch of the transfer lines. 


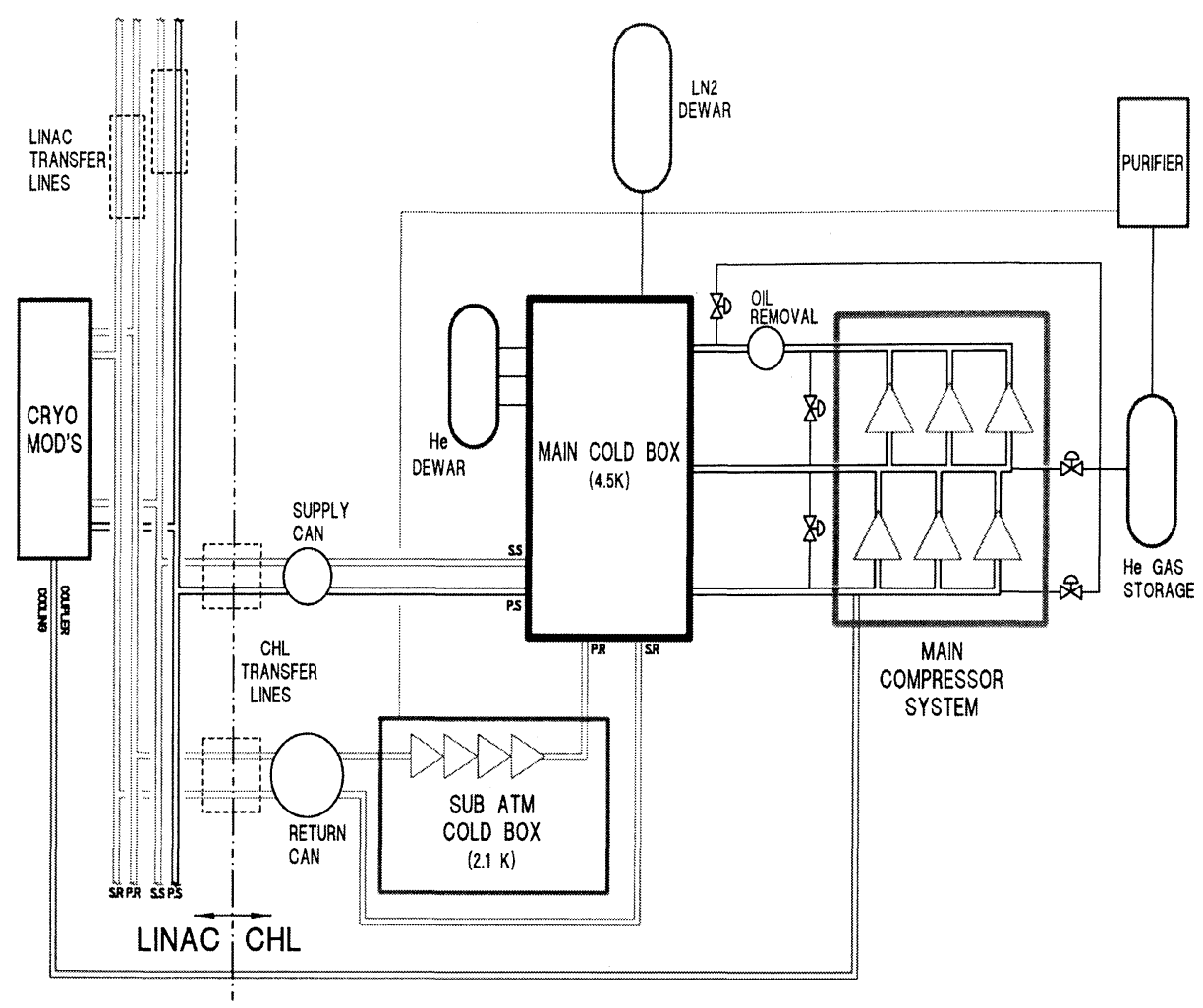

FIGURE 1. Cryogenic System Block diagram.

In December 2004, we started testing the $2.1 \mathrm{~K}$ Cold Box system with only 5 Cryomodules in the Linac tunnel and the same set of jumpers used to commission the cryogenic distribution system at $4.5 \mathrm{~K}$. After only a few days of tuning and system checks/verifications $2.1 \mathrm{~K}$ was achieved in the SNS Superconducting Linac.

TABLE 1. Refrigeration Parameters for 32 Cryomodules.

\begin{tabular}{|c|c|c|c|}
\hline & Primary & Secondary & Shield \\
\hline Temperature & $2.1 \mathrm{~K}$ & $4.5 \mathrm{~K}$ & $35-55 \mathrm{~K}$ \\
\hline Pressure & $0.041 \mathrm{bar}$ & $3 \mathrm{bar}$ & $4.0-3.0 \mathrm{bar}$ \\
\hline Static Load & $863 \mathrm{~W}$ & $5 \mathrm{~g} / \mathrm{s}$ & $6070 \mathrm{~W}$ \\
\hline Dynamic Load & $764 \mathrm{~W}$ & $2 \mathrm{~g} / \mathrm{s}$ & 0 \\
\hline Capacity & $2400 \mathrm{~W}$ & $15 \mathrm{~g} / \mathrm{s}$ & $8500 \mathrm{~W}$ \\
\hline
\end{tabular}




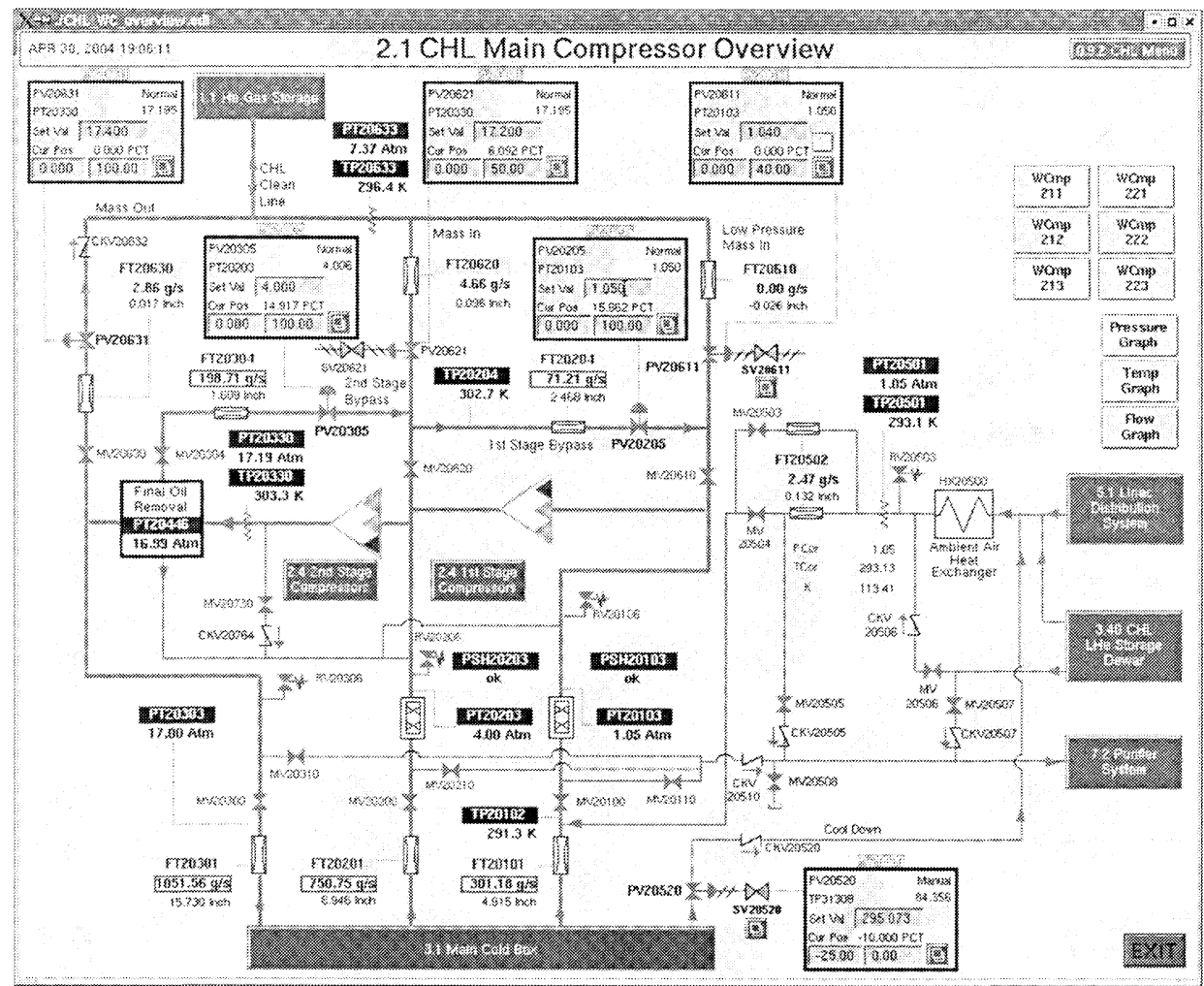

FIGURE 2. Control Screen.

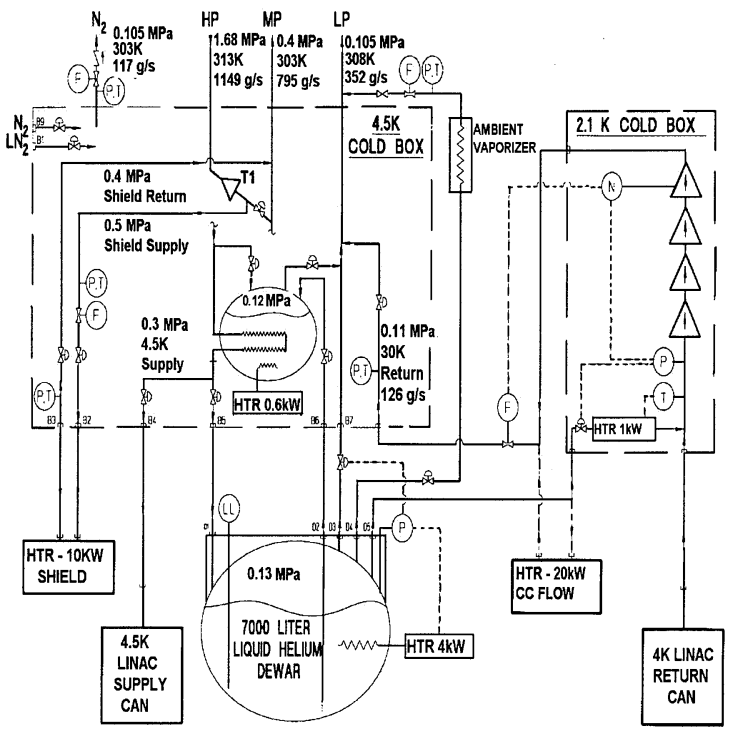

FIGURE 3. System Test Configuration. 
Since January 2005, we have been cooling down one additional cryomodule per week and focused primarily on RF testing integration at 4.5K [6].

Out of the 23 total Cryomodules, 22 have been tested at both $4.5 \mathrm{~K}$ and $2.1 \mathrm{~K}$. Insulating vacuum leaks (cold feedthroughs) on four of these cryomodules were repaired at SNS. The last Cryomodule has a Ti/Ti-Nb vessel leak and is being repaired at SNS.

The insulating vacuum integrity in the cryomodules is one of our main issues right now in the Superconducting Linac (SCL). Only one cryomodule to date has a leak from the insulating vacuum into the beam line.

In March and April 2005, we conducted a total of two more weeks of $2 \mathrm{~K}$ testing to study the system stability and performance [7].

The data analysis which is somewhat similar to the TJNAF system [8], confirms that the design load specification capacity of $2.4 \mathrm{KW}(120 \mathrm{~g} / \mathrm{s}$ of cold compressor flow) at $2.1 \mathrm{~K}$ is achieved even though some issues concerning the unexpectedly low power factor of the cold compressor motors are still under investigation. Automated control of the $2 \mathrm{~K}$ Cold Box was developed during the last testing period. The control is broken down into four specific sequences. The first sequence is the Backfill Sequence, shown in FIGURE 4.

This sequence backfills the return transfer line until a small positive differential pressure is established across the $2 \mathrm{~K}$ Cold Box. Helium from the dewar is used to complete this function. It then cools the $2 \mathrm{~K}$ cold box until the discharge temperature of cold compressor \#4 is less than 20K. The Backfill Sequence starts all four cold compressors (CC's) and sets them to their minimum speed after the cool down.

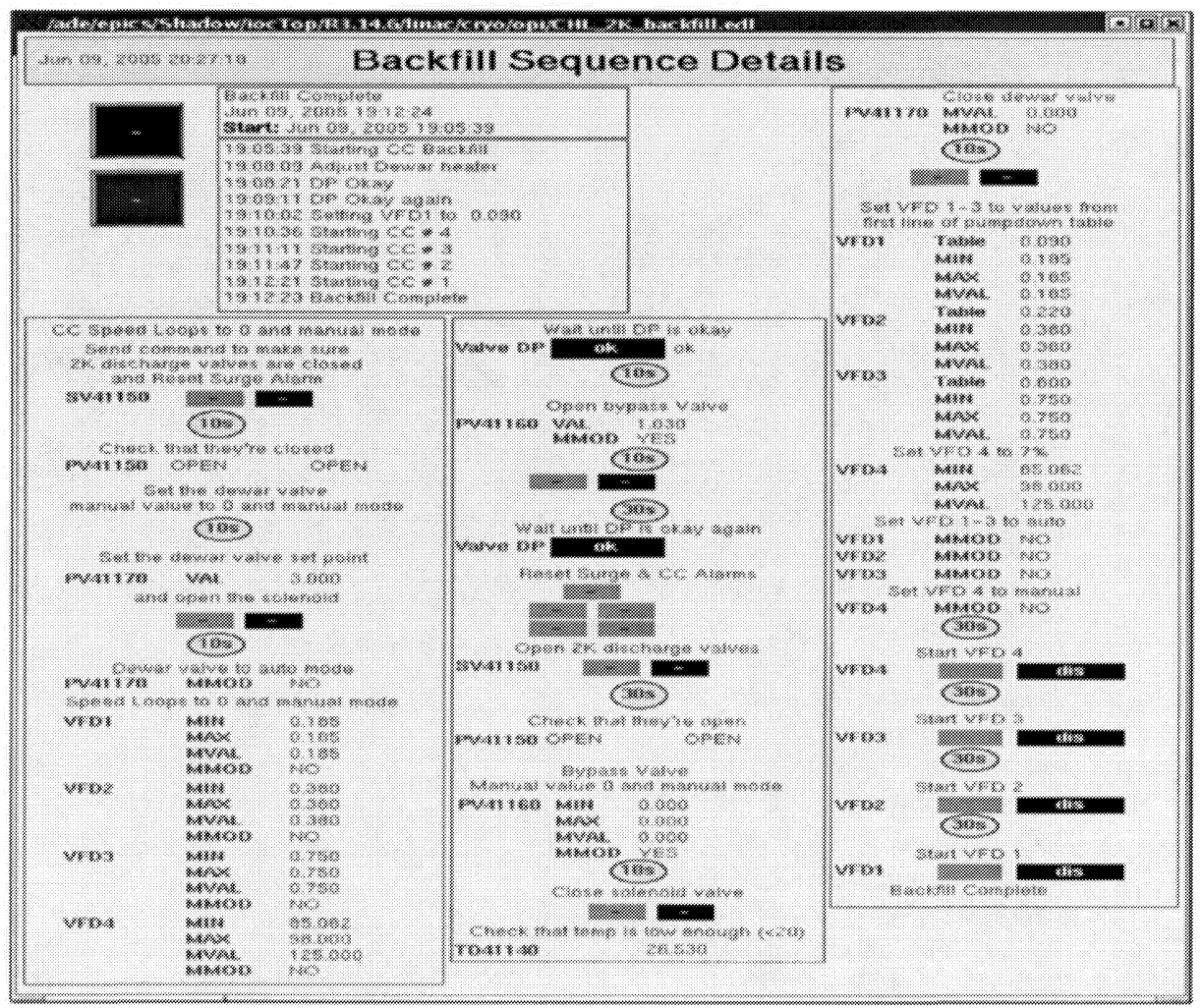

FIGURE 4. Backfill Sequence. 
The second sequence developed was the Cold Compressor Pump Down. This sequence controls flow from the LINAC through the $2 \mathrm{~K}$ Cold Box into the $4 \mathrm{~K}$ Cold Box low header injection point by adjusting the speed of cold compressor \# 4 . The other three cold compressors are controlled by gear ratios in relation to the speed of cold compressor \# 4. The specific ratios and control flow settings are triggered by the pressure in the return transfer line. The ratios and flow adjust until the target pressure of $0.041 \mathrm{bar}$ is achieved.

The third control sequence, the Cryo System Pump Down Sequence shown in FIGURE 5, controls the warm compressor pressures, helium dewar settings, turbine speeds, 4K Cold Box operating parameters including the turbine controls and the CC flow to low pressure injection points, and the cryomodule JT valves, liquid levels, and heater power. Settings are changed automatically as pressure in the return transfer line decreases.

The fourth and final sequence is the Main Heater Sequence. This sequence adjusts the heater power in the cryomodules to maintain the pressure of 0.041 bar in the return transfer line. This also has a swing heater feature that is used to handle fluctuations in pressure in the return line. This feature quickly adjusts one or two cryomodule heaters to gain control of the fluctuating pressure or the upset condition. After it gains control of the disturbance, the load is evenly distributed to all of the cryomodule heaters automatically. FIGURE 6 shows a fully automated pump down.

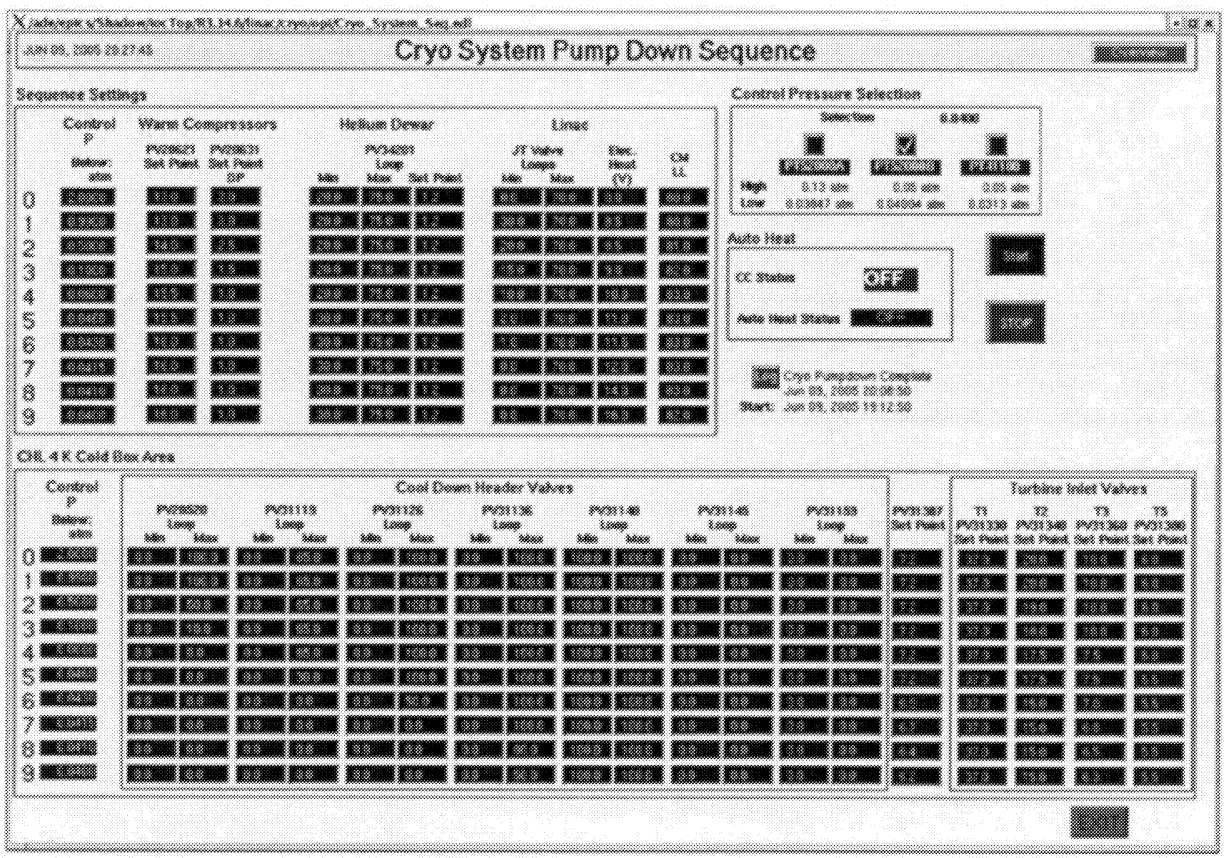

FIGURE 5. Cryo System Pump Down Sequence. 


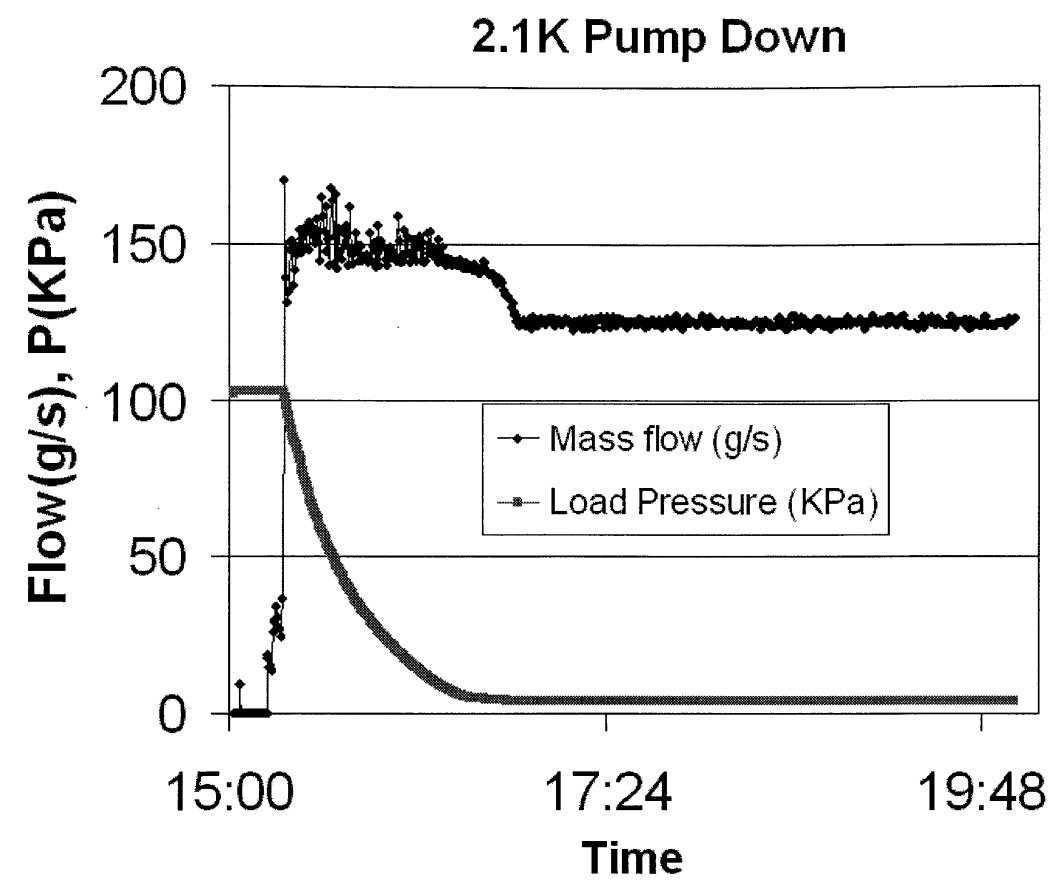

FIGURE 6. 2.1K Pump Down.

\section{FUTURE PLANS}

Currently we are supporting beam commissioning at $4.2 \mathrm{~K}$ through the end of August because it is more cost effective than $2 \mathrm{~K}$ operations. In the future as time permits we will study $2 \mathrm{~K}$ turn down capabilities, gear ratios, power factor correction, energy management and system optimizations.

\section{REMARKS}

The cryogenic system has been operating continuously since November 2004 and unmanned for at least one 8 hour shift per day since the end of December 2004. The system has proven to be very flexible and $4.5 \mathrm{~K}$ capacity can be turned down very easily. We have been using different combinations of turbines and system pressures depending on the load requirements and/or modes of operation. One of the most important technical components has been the $7000 \mathrm{~L}$ dewar design/interface and incorporation in the system not only for commissioning and testing purposes but to support normal operations.

\section{CONCLUSIONS}

The SNS cryogenic system has been successfully commissioned and has been operating to support RF testing and beam commissioning. The success of the project is the result of the careful design, excellent planning [9], execution and hard work of many 
people and the outstanding professionalism and technical expertise of the companies that supplied the subsystem components (PHPK, Linde/BOC, Air Liquide, S2M, Chart Industries, etc.)

\section{ACKNOWLEDGEMENTS}

SNS is managed by UT-Battelle, LLC, under contract DE-AC05-00OR22725 for the U.S. Department of Energy. SNS is a partnership of six national laboratories: Argonne, Brookhaven, Jefferson, Lawrence Berkeley, Los Alamos and Oak Ridge

Special thanks go to Dr.V.Ganni and the entire TJNAF cryogenic group for the design, technical support, profound cryogenic knowledge and help in the start up and operational setup of the system.

\section{REFERENCES}

1. Arenius, D. et al., "Cryogenic System for the Spallation Neutron Source," Advances in Cryogenic Engineering, Vol. 49, 2004.

2. Fleck, U. et al., "4.5K Cold Box for SNS-A Successful Cooperation," Advances in Cryogenic Engineering, Vol. 49, 2004.

3. White, M. "Spallation Neutron Source" Advances in Cryogenic Engineering, Vol. 47, 2002.

4. Daly, E. et al., "Spallation Neutron Source Cryomodule Heat Loads and Thermal Design," Advances in Cryogenic Engineering, Vol.47, 2002.

5. Howell, M., et al., "Spallation Neutron Source Cryogenic Transfer Lines," Advances in Cryogenic Engineering, Vol. 49, 2004.

6. Campisi, I., "Testing of the SNS Superconducting Cavities and Cryomodules," PAC2005, Knoxville, TN, May 2005.

7. Casagrande, F. et al., "Status of the Cryogenic System Commissioning at SNS," PAC2005, Knoxville, TN, May 2005.

8. Ganni, V. et al., "Design, Fabrication, Commissioning and Testing of a $250 \mathrm{~g} / \mathrm{s}, 2 \mathrm{~K}$ Helium Cold Compressor System," Advances in Cryogenic Engineering, Vol. 47, 2002.

9. Stout, D. et al., "Installation of the Spallation Neutron Source (SNS) Superconducting Linac," PAC2005, Knoxville, TN, May 2005. 